\title{
The Asthma Quiz for Kidz: A validated tool to appreciate the level of asthma control in children
}

\author{
Francine $M$ Ducharme $M D M S c^{1}, 2$, G Michael Davis $M D^{3}$, Francisco Noya MD ${ }^{4}$, Harold Rich $M D^{1}$, Pierre Ernst $M D^{2}$
}

FM Ducharme, GM Davis, F Noya, H Rich, P Ernst. The Asthma Quiz for Kidz: A validated tool to appreciate the level of asthma control in children. Can Respir J 2004;11(8):541-546.

BACKGROUND: There is an urgent need to bridge the large gap between optimal and observed asthma control among Canadian children.

OBJECTIVES: To adapt the criteria of asthma control proposed in the 1999 Asthma Consensus Statement for children and validate the proposed cut-offs in children with asthma.

METHODS: Six clinical criteria of asthma control were phrased as questions and response options, and pretested for clarity. A crosssectional study was conducted in children one to 17 years of age presenting to the hospital's asthma clinics. Children nine years of age or older and their parents were asked to complete The Asthma Quiz for Kidz separately, and then together, before the medical visit. Parents of younger children completed the questionnaire with their child. Physicians were not informed of the results of the quiz.

RESULTS: The mean age of the 343 participants was $8.0 \pm 4.4(\mathrm{SD})$ years with a mean baseline forced expiratory volume in $1 \mathrm{~s}$ of $96 \pm 15 \%$ of predicted values. Asthma severity was rated as mild $(67 \%)$, moderate $(29 \%)$ or severe $(4 \%)$. Overall, $57 \%$ of subjects endorsed at least two of the six criteria of poor control. The median (interquartile range) Asthma Quiz score was significantly higher when the physician's assessment of asthma control was poor than when the physician's assessment of asthma control was good $(3[1,5]$ versus $1[0,2], \mathrm{P}<0.001)$, but it did not correlate with the spirometry. A score of at least 2 out of 6 had $73 \%$ sensitivity and $59 \%$ specificity for identifying poor control.

INTERPRETATION: The Asthma Quiz score provides complementary information to, but does not replace, lung function testing. A score of 2 or more out of 6 suggests poor asthma control and should prompt patients to consult their physician for reassessment.
Quiz sur l'Asthme pour les Jeunes : Outil validé pour l'évaluation du contrôle de l'asthme chez les enfants

HISTORIQUE : Il devient urgent de combler l'important fossé qui sépare
le contrôle optimal de l'asthme chez les enfants canadiens et la situation
qui prévaut en réalité. OBJECTIFS : Adapter les critères de contrôle de l'asthme présentés dans l'énoncé consensuel sur l'asthme en pédiatrie qui date de 1999 et valider les valeurs seuils proposées chez les enfants asthmatiques.

MÉTHODES : Six critères cliniques ont été formulés sous forme de questions à choix multiples et la clarté des questions a été vérifiée. Une étude transversale a ensuite été menée auprès d'enfants âgés d'un à 17 ans se présentant dans les cliniques d'asthme de l'hôpital. Les enfants de neuf ans et plus et leurs parents ont été invités à répondre au Quiz sur l'asthme pour les jeunes chacun de leur côté, puis ensemble, avant la visite médicale. Ce sont les parents qui répondaient au questionnaire des plus jeunes. Les médecins n'étaient pas informés des résultats du questionnaire.

RÉSULTATS : L'âge moyen des participants était de 8,0 \pm 4,4 ans (É.-T.) et leur VEMS moyen au départ était de $96 \pm 15 \%$ des valeurs prévues. L'asthme a été jugé léger (67\%), modéré (29\%) ou sévère (4\%). Dans l'ensemble, $57 \%$ des sujets présentaient au moins deux des six critères d'un piètre contrôle de l'asthme. Les résultats médians du questionnaire sur l'asthme (écart interquartile) étaient significativement plus élevés lorsque de l'avis du médecin, le contrôle de l'asthme était insatisfaisant plutôt que satisfaisant $(3[1,5]$ versus $1[0,2], P<0,001)$, mais cela n'a pas été corrélation avec les résultats de la spirométrie. Un score d'au moins 2 sur 6 correspondait à une sensibilité de 73 \% et à une spécificité de $59 \%$ pour conclure à un piètre contrôle de l'asthme.

INTERPRÉTATION : Le score obtenu au moyen du Quiz sur l'Asthme pour les Jeunes offre un complément d'information, mais ne saurait se substituer au test de fonction pulmonaire. Un score de 2 sur 6 indique une piètre maîtrise de l'asthme et devrait inciter les patients à consulter leur médecin pour réévaluation.

Key Words: Adolescent; Asthma; Asthma control; Children; Symptoms; Questionnaire

Dises

espite widespread distribution of evidence-based guidelines, there is significant underutilization of long-term anti-inflammatory agents and continuing overdependence on symptom relief agents among children with asthma (1-3). In North America and Europe, asthma control remains far below the standards outlined in the major national and international asthma guidelines $(4,5)$. This situation results in unnecessary reductions in quality of life, and increased morbidity (6) and health care costs (7-9).

Why is adherence to guidelines so universally poor? One possible explanation may be that children with asthma and their parents perceive symptoms poorly and have limited expectations (4). Indeed, several surveys $(4,10)$ have highlighted the fact that most asthmatics perceive their asthma as well controlled even if

Departments of ${ }^{1}$ Pediatrics; ${ }^{2}$ Epidemiology and Biostatistics; ${ }^{3}$ Pediatrics, Division of Respiratory Medicine; and ${ }^{4}$ Pediatrics, Services of Allergy and Clinical Immunology and Infectious Diseases, Montreal Children's Hospital, McGill University Health Centre, Montreal, Quebec

Correspondence and reprints: Dr Francine M Ducharme, Department of Pediatrics, Montreal Children's Hospital - McGill University Health

Centre, 2300 Tupper Street, Montreal, Quebec H3H 1P3. E-mail Francine.ducharme@muhc.mcgill.ca 


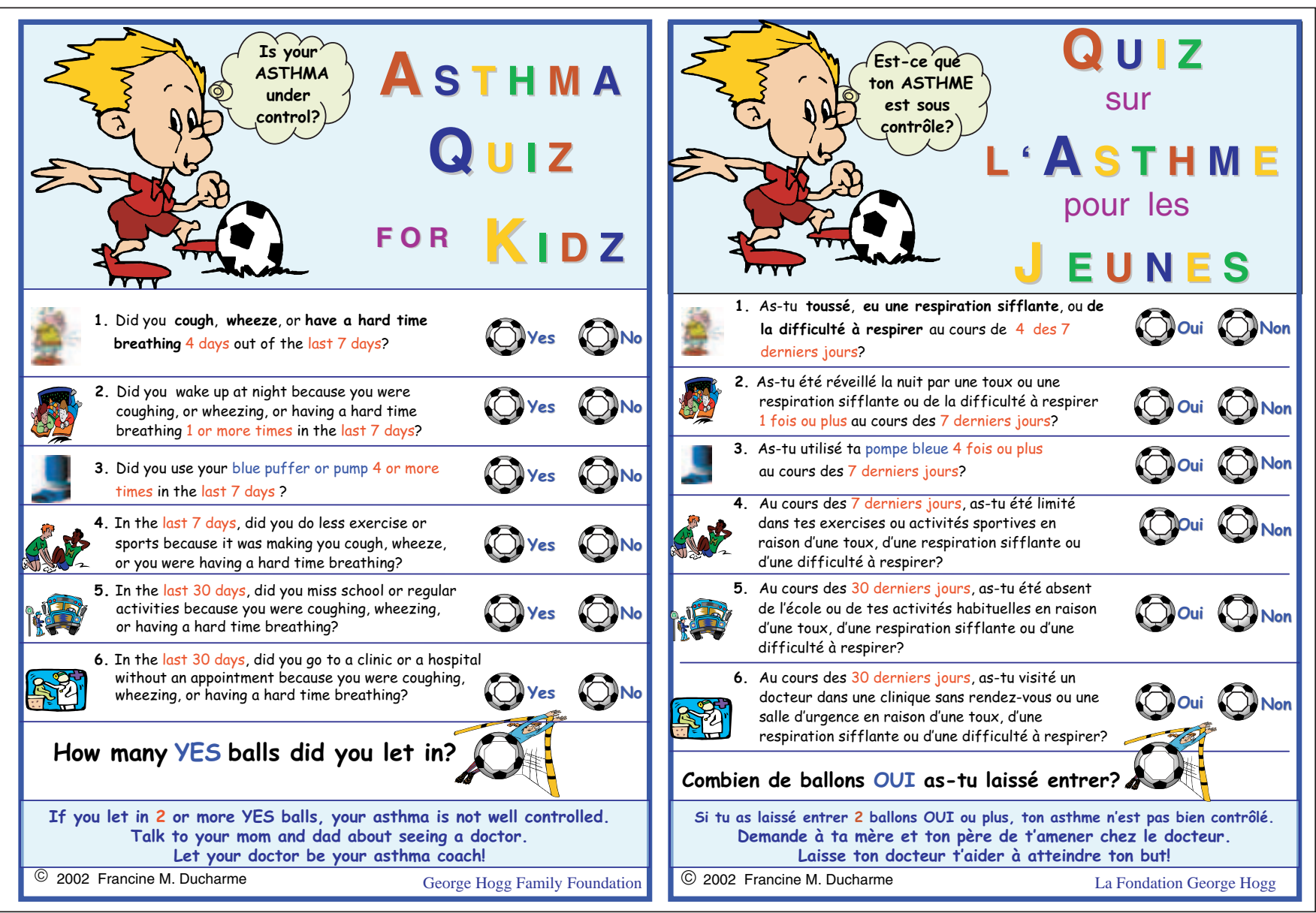

Figure 1) English and French versions of The Asthma Quiz for Kidz

they report significant lifestyle restrictions and major health care resource consumption. Furthermore, patients generally do not discuss their restrictions in lifestyle with physicians $(10,11)$. This may explain the huge gap between actual and optimal asthma care.

In the 1999 Asthma Consensus Statement (12), eight criteria of asthma control were proposed. These criteria were similar to those issued by other major guidelines (13-15). Six of the eight criteria pertained to clinical features easily reported by the patients and the remaining two pertained to lung function tests. The aims of the present study were to validate the six clinical criteria and their proposed cut-offs for assessing asthma control in children. More specifically, we wished to develop a self-assessment instrument for children to appraise their level of asthma control and validate these criteria using the physician's assessment of disease control.

\section{METHODS}

The study was approved by the institutional review board of The Montreal Children's Hospital (Montreal, Quebec). Informed consent was obtained from parents or legal guardians.

\section{Instrument development}

The cut-off values of four criteria for control were stated by the Canadian Asthma Consensus (12): daytime symptoms less than four days/week; night-time symptoms less than one night/week; res-

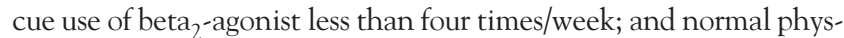
ical activity. Cut-offs for the other two criteria were operationally defined as no school absenteeism due to asthma in the preceding 30 days and no exacerbation requiring an unscheduled medical visit in the preceding 30 days.

Item presentation and scaling

Each criterion was phrased in the form of a question. All response options were scaled as yes ( 1 point $)$ or no ( 0 points $)$, for a maximum score of 6 , assuming an equal weight for each variable. Each language version was translated and back-translated to ensure concordance between both the English- and French-language versions. Editorial changes occurred until concordance was achieved.

Pretesting for clarity

Clarity was tested with cognitive interviews, during which asthmatic children six to 17 years of age and their parents were interviewed separately, asked to read each question and response option aloud, and prompted to 'think aloud' while choosing their answer (16). These answers were then challenged to ensure correct understanding of the questions. Several iterative versions were produced until at least $90 \%$ clarity was achieved regarding the questions, response options and interpretations. The fourth and final version was called 'The Asthma Quiz for Kidz' (Figure 1).

Pretesting for psychometric properties

Design: A cross-sectional study of patients presenting with asthma to the Montreal Children's Hospital's asthma and chest clinics (Montreal, Quebec) was conducted. Follow-up information was obtained from the patients who returned to the clinics during the study period. 
Subjects: Children were eligible if they had asthma according to the American Thoracic Society definition (17), were one to 17 years of age and they (or their parents) had adequate English or French language skills. Children with bronchopulmonary dysplasia or cystic fibrosis were excluded.

Measurements: Children aged nine years and older and their parents completed the Asthma Quiz separately, and then together, before seeing the physician. Parents of younger children (eight years of age or younger) completed the quiz with their child. Another questionnaire inquired about perceived asthma severity (mild, moderate or severe), as well as asthma control and the child's ability to keep up with other children (on 4-point scales).

In cooperative children, spirometry was performed on the Masterscreen (Jaeger GmH, Germany) or V-Max 22 (SensorMedics Inc, USA) before and after bronchodilation with $400 \mu \mathrm{g}$ salbutamol (or $200 \mu \mathrm{g}$ of terbutaline sulfate). Values that met the American Thoracic Society definition of reproducibility were recorded (18). The treating physician, blinded to the result of the Asthma Quiz, recorded the symptoms (cough, dyspnea and/or wheezing), type of asthma (episodic, persistent or seasonal), severity, control and codiagnoses. Severity was assessed by the intensity of treatment required to maintain disease control, namely, mild (requiring no or low [less than $400 \mu \mathrm{g} /$ day of chlorofluorocarbonpropelled beclomethasone diproprionate or equivalent (CFC$\left.\mathrm{BDP}_{\mathrm{eq}}\right)$ ] doses of inhaled steroids or nonsteroidal drugs); moderate (requiring inhaled steroids in moderate [ $400 \mu \mathrm{g} /$ day or more, but less than $800 \mu \mathrm{g} /$ day of CFC-BDP ${ }_{\text {eq }}$ ] doses or in low doses with add-on therapy); and severe (requiring inhaled steroids in high [800 $\mu \mathrm{g} /$ day or more of CFC-BDP ${ }_{\mathrm{eq}}$ ] doses or in moderate doses with add-on therapy) $(12,14)$. Control was rated as good or poor based on the physician's global evaluation using history, examination and lung function tests $(12,14)$. Codiagnoses such as allergic rhinitis, sinusitis, gastroesophageal reflux and vocal cord dysfunction were recorded.

\section{Statistics}

A sample size of 75 children per language (French and English) and age (one to eight years of age versus nine to 17 years of age) groups was required to identify, with a power of $80 \%$ and an alpha of 5\%, a group difference of 2 in the Asthma Quiz score those with poor versus good control.

The internal consistency of the instrument was measured by the Cronbach alpha coefficient (19). The Kappa coefficient weighted with quadratic means (20) served to examine the inter-rater reliability (ie, the concordance of the Asthma Quiz score between the consensus of parent $[\mathrm{s}$ ] and child [taken as the gold standard], and the child alone and the parent[s] alone) and the test-retest reliability among stable children, in whom the change in forced expiratory volume in $1 \mathrm{~s}\left(\mathrm{FEV}_{1}\right)$ between the index and the follow-up visits was less than $12 \%(21,22)$. The distribution of the score was compared between groups with the Wilcoxon rank sum test (23) or the Mantel Haenszel $\chi^{2}$ statistics, as indicated. The Spearman rho was used to examine the correlation between the Asthma Quiz score and spirometric values (23). The sensitivity and specificity of the cut-off values were reported with 95\% CIs (24). The responsiveness of the Asthma Quiz was examined among children who changed between the two visits (ie, those in whom the change in $\mathrm{FEV}_{1}$ between the two visits was $12 \%$ or greater) $(21,22)$. The Guyatt's responsiveness index was reported (25), calculated as the mean change in patients who had changed divided by the $\mathrm{SD}$ of the change in stable patients; the CIs were calculated

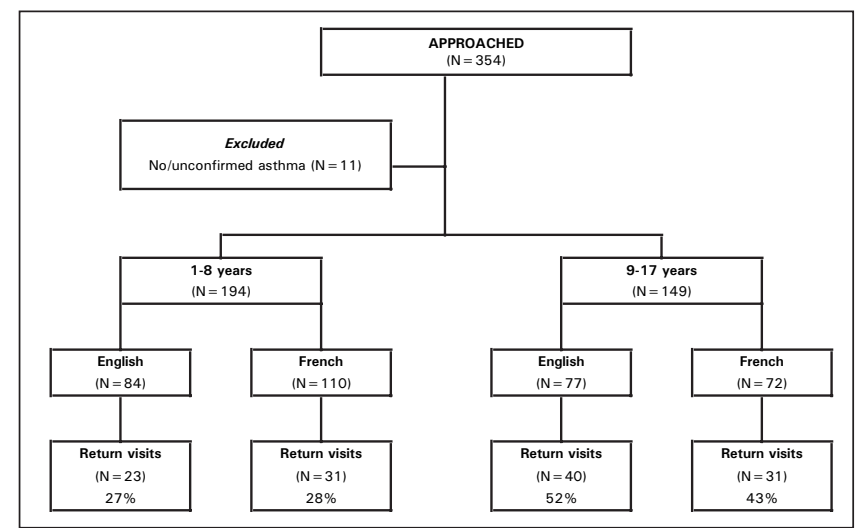

Figure 2) Flow diagram of participants for testing of psychometric properties

using the bootstrap method (26). Medians were reported with interquartile range ( $25 \mathrm{th}, 75$ th percentile). $\mathrm{P}<0.05$ was considered statistically significant.

\section{Pretesting for clarity}

\section{RESULTS}

Cognitive interviews were performed with 42 children and their parents recruited from the emergency room $(n=9)$, hospital wards $(n=7)$ and clinics $(n=26)$. Children had a median age of $10(8,14)$ years, with $4(2,7)$ completed years of education; $50 \%$ of the children were males. The language spoken was English (48\%), French (48\%) and other (4\%). The fourth version, tested in 11 children, revealed more than $90 \%$ clarity on each item, response option and interpretation. The final layout and guidelines for interpretation yielded $100 \%$ clarity in a final group of 54 children.

Although children nine years of age and older accurately completed the questionnaire alone, children six to eight years of age frequently required parental assistance to identify landmark events that would ensure accurate reports of symptoms occurring in the specific time period studied. Because the children's contribution was critical to remembering the events that occurred away from parental supervision, parents of children age eight years of age and younger were asked to complete the quiz with their child's input.

\section{Pretesting for psychometric properties}

Between July 2001 and February 2002, 354 children were approached, with $100 \%$ of eligible children agreeing to participate (Figure 2). As part of their standard assessment, children completed the Asthma Quiz, usually within 2 min. The characteristics of the 343 participants, detailed in Table 1, showed no significant difference between language groups. There was also no group difference by language in the distribution of score or, with the exception of school absences, in the endorsement of criteria. Slightly more members of ethnic Englishspeaking minorities refrained from sending their child to school in the preceding month, perhaps suggesting a cultural bias (English 33\% versus French 22\%, P<0.05). In view of the similar patient characteristics and score distribution, both languages were combined for all subsequent analyses.

Although $71 \%$ of children had an $\mathrm{FEV}_{1}$ of $80 \%$ or greater of predicted values and an $\mathrm{FEV}_{1}: \mathrm{FVC}$ (forced vital capacity) ratio of $80 \%$ or greater, $57 \%$ had endorsed at least two criteria of 
TABLE 1

Characteristics of participants enrolled in the testing for psychometric properties

\begin{tabular}{|c|c|c|}
\hline & $\begin{array}{l}\text { English } \\
(n=161)\end{array}$ & $\begin{array}{l}\text { French } \\
(\mathrm{n}=182)\end{array}$ \\
\hline Sex (\% male) & 56 & 56 \\
\hline Age (years) (mean $\pm S D$ ) & $8.4 \pm 4.5$ & $7.5 \pm 4.2$ \\
\hline \multicolumn{3}{|l|}{ Race, \% } \\
\hline White & 70 & 82 \\
\hline Black & 10 & 8 \\
\hline Others & 20 & 10 \\
\hline \multicolumn{3}{|l|}{ Asthma type, \% } \\
\hline Episodic & 54 & 53 \\
\hline Persistent/seasonal & 46 & 47 \\
\hline \multicolumn{3}{|l|}{ Symptoms, \% } \\
\hline Cough or dyspnea alone & 21 & 26 \\
\hline Cough, dyspnea and wheezing & 79 & 74 \\
\hline \multicolumn{3}{|l|}{ Codiagnoses, $\%$} \\
\hline Allergic rhinitis & 35 & 26 \\
\hline Recurrent sinusitis & 6 & 6 \\
\hline Gastroesophageal reflux & 2 & 3 \\
\hline Vocal cord dysfunction & 0.5 & 0 \\
\hline \multicolumn{3}{|l|}{ Maintenance prescription, \% } \\
\hline None & 59 & 60 \\
\hline Nonsteroidal* & 6 & 5 \\
\hline Inhaled glucocorticoids & 27 & 24 \\
\hline $\begin{array}{l}\text { Inhaled glucocorticoids with } \\
\text { long-acting } \text { beta }_{2} \text {-agonists }\end{array}$ & 7 & 10 \\
\hline Oral steroids & 1 & 1 \\
\hline Spirometry (mean \pm SD) & $(n=111)$ & $(n=103)$ \\
\hline $\mathrm{FEV}_{1}(\%$ of predicted) & $96 \pm 15$ & $96 \pm 16$ \\
\hline $\mathrm{FEV}_{1} / \mathrm{FVC}$ ratio, $\%$ & $84 \pm 9$ & $83 \pm 9$ \\
\hline$\%$ change in $\mathrm{FEV}_{1}$ post-bronchodilalation & $7 \pm 6$ & $8 \pm 7$ \\
\hline \multicolumn{3}{|l|}{ MD assessment of asthma severity, $\%$} \\
\hline Mild & 66 & 68 \\
\hline Moderate & 29 & 28 \\
\hline Severe & 5 & 4 \\
\hline \multicolumn{3}{|l|}{ MD assessement of control, \% } \\
\hline Good & 61 & 65 \\
\hline Poor & 39 & 35 \\
\hline
\end{tabular}

${ }^{*}$ Cromoglycate, ketotifen, nedocromil or antileukotrienes. FEV 1 Forced expiratory volume in $1 \mathrm{~s}$; FVC Forced vital capacity; MD Physician

poor asthma control. The distribution of the score appeared to be independent of the physician assessment of severity (mild $1.95 \pm 0.12$; moderate $2.16 \pm 0.18$; and severe 2.36 \pm 0.53 , $\mathrm{P}=0.26)$.

Internal consistency

The internal consistency of the Asthma Quiz was good (Cronbach alpha $=0.73$ ); each item contributed significantly (alpha $>0.7$ ) to the overall instrument (27).

\section{Reliability}

The inter-rater reliability was examined among children aged nine years and older. The responses of all respondents correlated strongly with the consensus of parents and child, with the parental self-report correlating more strongly than the child self-report; however, the trend was reversed for adolescents 14 to 17 years of age (Table 2). There was no significant difference between respondents in the endorsement of criteria (Figure 3). Among the 70 children considered to be stable on
TABLE 2

Concordance on the Asthma Quiz score between the child, the parent(s) and the consensus of child and parent(s)

\begin{tabular}{|c|c|c|c|c|c|c|}
\hline \multirow{2}{*}{$\begin{array}{l}\text { Consensus of child } \\
\text { and parent(s) }\end{array}$} & \multicolumn{3}{|c|}{ Child } & \multicolumn{3}{|c|}{ Parent(s) } \\
\hline & $\mathbf{n}$ & Kappa* & $95 \% \mathrm{Cl}$ & $\mathbf{n}$ & Kappa* & $95 \% \mathrm{Cl}$ \\
\hline \multicolumn{7}{|l|}{ Overall } \\
\hline Nine to 17 years & 127 & 0.83 & 0.77 to 0.88 & 126 & 0.920 & 0.89 to 0.94 \\
\hline \multicolumn{7}{|l|}{ By age subgroup } \\
\hline Nine to 13 years & 101 & 0.85 & 0.79 to 0.90 & 101 & 0.930 & 0.90 to 0.95 \\
\hline 14 to 17 years & 24 & 0.84 & 0.66 to 0.93 & 25 & 0.720 & 0.47 to 0.88 \\
\hline
\end{tabular}

*Kappa coefficient weighted with quadratic means

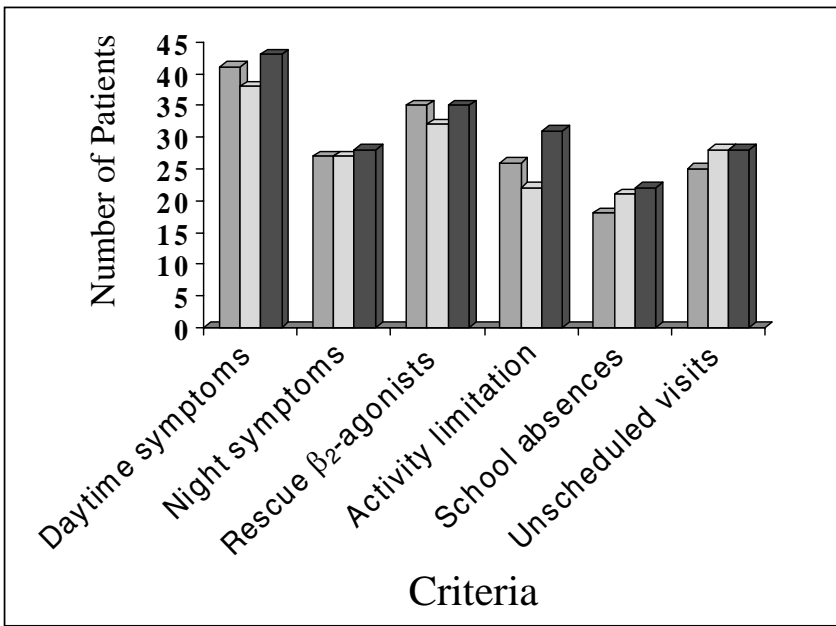

Figure 3) This bar graph depicts the number of endorsements of each criteria of poor control listed on the $x$-axis by respondents aged nine years and older: child (dark grey bar), parents (light grey bar) versus the consensus of child and parents (black solid bar). There was no overall significant difference between groups in the endorsement of each criteria, namely, daytime symptoms less than four days/week; nighttime symptoms less than one night/week; rescue use of beta-agonist ( $\beta_{2}$-agonists) less than four times/week; limitation of physical activity; school or work absenteeism in the preceding 30 days; and exacerbation requiring an unscheduled medical visit in preceding 30 days

the second visit, the test-retest reliability of the Asthma Quiz was satisfactory $(0.51,95 \% \mathrm{CI} 0.33$ to 0.70$)$.

Discriminative properties

Using parent-child consensus as the gold standard, the median Asthma Quiz score was found to be significantly higher when the physician's assessment of asthma control was poor as opposed to good $(3[1,5]$ versus $1[0,2], \mathrm{P}<0.0001)$; when the child's ability to keep up with others was impaired $(4[2,5]$ versus $2[0,3], \mathrm{P}<0.0001)$; and when self-assessment of asthma revealed poor control $(4[2,5]$ versus $1[0,3], \mathrm{P}<0.0001)$. The Asthma Quiz score was significantly associated with the parentchild perception of asthma severity $(\mathrm{P}<0.0001)$. Interestingly, there was no correlation between the parent-child's and physicians' assessment of asthma severity.

A score of 2 or more on the Asthma Quiz had a sensitivity of $73 \%(61 \%, 82 \%)$ and a specificity of $59 \%(50 \%, 67 \%)$ for detecting poor control as assessed by the physician (Figure 4). A score of 1 or greater was associated with a $84 \%(73 \%, 91 \%)$ 
sensitivity but a notably lower specificity 38\% (30\%, 46\%). The sensitivity was not significantly affected by the child's age (one to five years of age: $71 \%$ versus six to 17 years of age: $73 \%$ ), presence of codiagnoses (present: $73 \%$ versus absent: $72 \%$ ) or severity (mild: $76 \%$ versus moderate-severe: $67 \%$ ). Among the 15 children whose conditions changed significantly between the two visits, the Guyatt's statistic was 1.66 (95\% CI 0.91 to $2.55)$, indicating good responsiveness to change.

\section{DISCUSSION}

The Asthma Quiz for Kidz, designed specifically for children, appears to be a valid, reliable and responsive measure of asthma control. It has good internal consistency; that is, it is not affected by the type of asthma, respondents or codiagnoses. It has good test-retest reliability among children who are considered to be stable and is responsive to change in disease control. The Asthma Quiz for Kidz correlates with physician assessment of asthma control. Although it is not sufficiently sensitive to serve as a unique screening tool, a cut-off of two or more positive responses is suggestive of poor disease control and should prompt patients to consult their physicians.

Despite normal spirometry, $57 \%$ of children had at least two criteria suggestive of poor control. Similar findings were observed in other asthma clinic studies, where up to nine of 10 children reported symptoms despite near-normal lung function (28), as well as very poor correlation between symptoms and lung function (29). The similar internal consistency, the positive responses and the cut-off values in children with and without codiagnoses all suggest that the reported symptoms were indeed related to asthma and not misinterpreted symptoms of rhinitis, sinusitis, gastroesophageal reflux or vocal cord dysfunction. These observations suggest that the presence of symptoms may be more sensitive than lung function testing. The Asthma Quiz may provide complementary information to, but does not replace, lung function testing.

Symptoms, activity limitation, rescue medication and health care use were identified by the major consensus guidelines as indicators of poor asthma control (12-15). While The Asthma Quiz for Kidz appears to be the first pediatric instrument to measure asthma control, two adult instruments (the Asthma Therapy Assessment Questionnaire [8] and the Asthma Control Questionnaire [30]) have also integrated these four dimensions. Both adult instruments, which also assume a similar weight for each variable, were successfully validated against quality of life $(8,30)$ and health care use $(31)$.

While it is increasingly recognized that quality of life is best reported by the children and adolescents themselves rather than by parents (32), the high concordance among respondents would suggest that bias was not strong in children who spend a large proportion of their time with parents. Children nine years of age and older could complete the Asthma Quiz by themselves with good concordance with the consensus of parents and child. Parents were a good proxy, except perhaps in the case of children 14 years of age and older, in which they agreed with the consensus less than the adolescents. In children younger than nine years of age, the Asthma Quiz should be completed by the parents with the child's input, whenever possible.

\section{Strengths and limitations}

The Asthma Quiz reflects symptoms that have occurred in the preceding seven days as well as events of the past 30 days. These short time frames were needed because of the inability

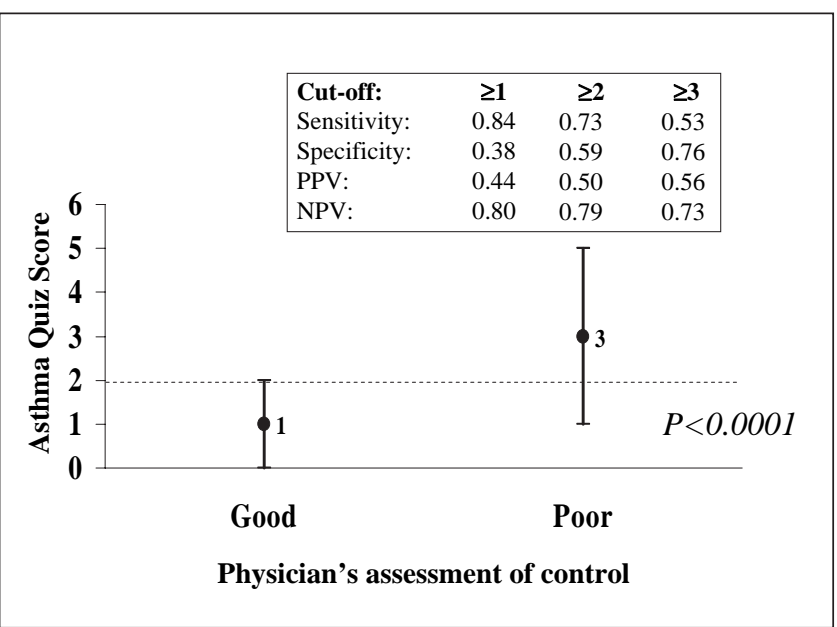

Figure 4) Distribution of the Asthma Quiz score according to the physician's assessment of control. The solid circle indicates the median score with the error bars indicating the $25 \%$ and $75 \%$ of the score within each group. The difference between good and poor control was highly significant by the Wilcoxon signed rank test $(P<0.0001)$. The cut-off score of 2 out of 6 had $73 \%$ sensitivity and $59 \%$ specificity for correctly identifying poor asthma control. NPV Negative predictive value; PPV Positive predictive value

of young children to recall longer periods. We sampled the preceding, rather than the average week because of the children's confusion when the frequency of symptoms was not consistent across weeks. Clearly, the Asthma Quiz represents a cross-sectional view of children's asthma control; it needs to be repeated for a more representative view of the overall pattern of control.

A child's perception of symptoms may very well affect the Asthma Quiz score; discordance among the Asthma Quiz score, medical assessment and lung function testing should be addressed by physicians. Indeed, some children with poor lung function reported a low Asthma Quiz score. Perhaps the poor concordance between the parent-child's and physician's assessment of asthma severity may be explained by the confusing, and seemingly similar, notions of severity and control. Symptom perception and severity assessment are essential for preparing an effective action plan for the child. The Asthma Quiz should serve primarily as a communication tool to help elicit a better history; it should be considered along with the physical examination and lung function testing.

The change in the Asthma Quiz score measured over time distinguished children who notably improved from those who had deteriorated between the two visits. However, with only $18 \%$ (15 of 85 ) of the patients changing significantly between the two visits, there is a need to confirm the responsiveness and the cut-off value indicative of a significant change.

Clearly a clinical tool based on symptom perception will never have the accuracy of expert medical opinion coupled with objective pulmonary function testing. No cut-offs are ideal. The choice of the cut-off value depends on the purpose and the balance between the risk of falsely labelling a child as well-controlled, as opposed to not well-controlled. We proposed a cut-off score of 2 instead of 1 to reduce the risk of falsely worrying patients about poor asthma control from $62 \%$ to $41 \%$; this was associated with a slight reduction in sensitivity from $84 \%$ to $73 \%$, a level insufficient for a screening tool. We believe the Asthma Quiz should serve as a reminder for the 
child and parents to periodically reassess the level of asthma control and as a communication aid among children, parents and health care professionals. It may also serve to remind physicians of the criteria for asthma control, a concept that is not always in keeping with asthma guidelines (33). Whether use of the quiz as a communication tool will actually change physicians' or patients' management of asthma and improve quality of life is currently being tested in an ongoing randomized trial.

\section{CONCLUSIONS}

The Asthma Quiz for Kidz is a simple, self-administered questionnaire that correlates with the physician's assessment of asthma control and is easily completed by school-aged children and by parents of younger children. The Asthma Quiz is primarily intended for monitoring a child's asthma control and for serving as a communication tool among the child, parents and physician. It should prompt children and parents to seek a physician's advice when asthma control is suboptimal.

\section{REFERENCES}

1. Warman KL, Silver EJ, Stein RE. Asthma symptoms, morbidity, and antiinflammatory use in inner-city children. Pediatrics 2001;108:277-82.

2. Meng YY, Leung KM, Berkbigler D, Halbert RJ, Legorreta AP. Compliance with US asthma management guidelines and specialty care: A regional variation or national concern? J Eval Clin Pract 1999;5:213-21.

3. Vermeire PA, Rabe KF, Soriano JB, Maier WC. Asthma control and differences in management practices across seven European countries. Respir Med 2002;96:142-9

4. Chapman KR, Ernst P, Grenville A, Dewland P, Zimmerman S. Control of asthma in Canada: Failure to achieve guideline targets. Can Respir J 2001;8(Suppl A):35A-40A.

5. von Mutius E. Presentation of new GINA guidelines for paediatrics. The Global Initiative on Asthma. Clin Exp Allergy 2000;30(Suppl 1):6-10.

6. Diette GB, Skinner EA, Markson LE, et al. Consistency of care with national guidelines for children with asthma in managed care. J Pediatr 2001;138:59-64.

7. Krahn MD, Berka C, Langlois P, Detsky AS. Direct and indirect costs of asthma in Canada, 1990. CMAJ 1996;154:821-31.

8. Vollmer WM, Markson LE, O'Connor E, et al. Association of asthma control with health care utilization and quality of life. Am J Respir Crit Care Med 1999;160:1647-52.

9. Homer CJ, Szilagyi P, Rodewald L, et al. Does quality of care affect rates of hospitalization for childhood asthma? Pediatrics 1996;98:18-23.

10. Jones KG, Bell J, Fehrenbach C, Pearce L, Grimley D, McCarthy TP. Understanding patient perceptions of asthma: Results of the Asthma Control and Expectations (ACE) survey. Int J Clin Pract 2002;56:89-93

11. Hayward RS, Wilson MC, Tunis SR, Bass EB, Guyatt G. Users' guides to the medical literature. VIII. How to use clinical practice guidelines. A. Are the recommendations valid? The Evidence-Based Medicine Working Group. JAMA 1995;274:570-4.

12. Boulet LP, Becker A, Berube D, Beveridge R, Ernst P. Canadian Asthma Consensus Report, 1999. Canadian Asthma Consensus Group. CMAJ 1999;161(11 Suppl):S1-S61.

13. Asthma Management Handbook 2002, 5th edn. Melbourne: National Asthma Council, 2002. $<$ www.nationalasthma.org.au/publications/amh/amhcont.htm>. (Version current at September 28, 2004).

14. National Asthma Education and Prevention Program. NAEPP Expert Panel Report Guidelines for the Diagnosis and Management of Asthma. NIH Publication 02-5075. Bethesda: National Heart, Lung and Blood Institute, 2002.

<www.nhlbi.nih.gov/guidelines/asthma/index.htm> (Version current at September 28, 2004).

15. BTS guidelines for the management of chronic obstructive pulmonary disease. The COPD Guidelines Group of the Standards of Care Committee of the BTS. Thorax 1997;52(Suppl 5):S1-S28.
FUNDING: Dr Francine M Ducharme was supported by a senior clinician-scientist award of the Fonds de la recherche en santé du Québec. The project was funded, in part, by the George Hogg Family Foundation and by GlaxoSmithKline, Canada.

ACKNOWLEDGEMENTS: The authors sincerely thank Alya Danish, Grenchen Kramer, Helen Magdelinos, Catherine Mereb and Sandy Resendes for their cognitive interviews, iterative revisions of the Asthma Quiz, and diligent data collection and entry. The authors are indebted to Rita Zakarian for the meticulous supervision of data collection and creative layout for the Asthma Quiz. The authors thank Justin Grondines for his meticulous data management and analyses, and Francine Lacoste for back-translation of the quiz in its iterative versions. The authors acknowledge the support of David McGillivray and Dominic Chalut, directors of the Emergency Department, and Gary Pekeles, director of the Short Stay Unit for allowing access to the emergency department and hospitalized patients.

16. Jobe JB. Cognitive psychology and self-reports: Models and methods. Qual Life Res 2003;12:219-27.

17. Standards for the diagnosis and care of patients with chronic obstructive pulmonary disease (COPD) and asthma. This official statement of the American Thoracic Society was adopted by the ATS Board of Directors, November 1986. Am Rev Respir Dis 1987:136:225-44.

18. Hankinson JL, Bang KM. Acceptability and reproducibility criteria of the American Thoracic Society as observed in a sample of the general population. Am Rev Respir Dis 1991;143:516-21.

19. Cronbach LJ. Coefficient alpha and the internal structure of tests. Psychometrika 1951;16:297-334

20. Streiner DL, Norman GR. Reliability. In: Streiner DL, Norman GR, eds. Health Measurement Scales. Oxford: Oxford University Press, 1989:79-96.

21. Strachan DP. Repeatability of ventilatory function measurements in a population survey of 7 year old children. Thorax 1989;44:474-9.

22. Timonen KL, Randell JT, Salonen RO, Pekkanen J. Short-term variations in oscillatory and spirometric lung function indices among school children. Eur Respir J 1997;10:82-7.

23. Colton T. Nonparametric methods. In: Colton T, ed. Statistics in Medicine. Boston: Little, Brown and Company, 1974:219-27.

24. Newcombe RG. Two-sided confidence intervals for the single proportion: Comparison of seven methods. Stat Med 1998;17:857-72.

25. Guyatt G, Walter S, Norman G. Measuring change over time: Assessing the usefulness of evaluative instruments. J Chron Dis 1987;40:171-8

26. Efron B. An Introduction to the Bootstrap. New York: Chapman \& Hall, 1993.

27. Johnson SB. Methodological considerations in pediatric behavioral research: Measurement. J Dev Behav Pediatr 1991;12:361-9.

28. Mitra AD, Ogstron S, Crighton A, Mukhopadhyay S. Lung function and asthma symptoms in children: Relationships and response to treatment. Acta Paediatr 2002;91:789-92.

29. Korppi M, Remes K. Asthma treatment in schoolchildren: Lung function in different therapeutic groups. Acta Paediatr 1996;85:190-4.

30. Juniper EF, O’Byrne PM, Guyatt GH, Ferrie PJ, King DR. Development and validation of a questionnaire to measure asthma control. Eur Respir J 1999;14:902-7.

31. Vollmer WM, Markson LE, O'Connor E, Frazier EA, Berger M. Association of asthma control with health care utilization: A prospective evaluation. Am J Respir Crit Care Med 2001;165:195-9.

32. Feeny D, Juniper EF, Ferrie PJ, Griffith LE, Guyatt GH. Why not just ask the kids? Health-related quality of life in children with asthma. In: Drotar D, ed. Measuring Health-related Quality of Life in Children and Adolescents. Implications for Research and Practice. New Jersey: Lawrence Erlbaum Associates, 1998:171-85.

33. Boulet LP, Phillips R, O'Byrne P, Becker A. Evaluation of asthma control by physicians and patients: comparison with current guidelines. Can Respir J 2002;9:417-23. 


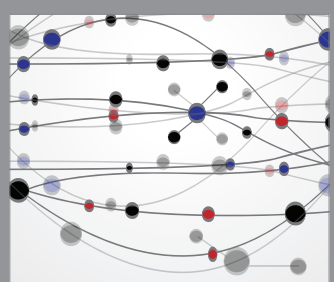

The Scientific World Journal
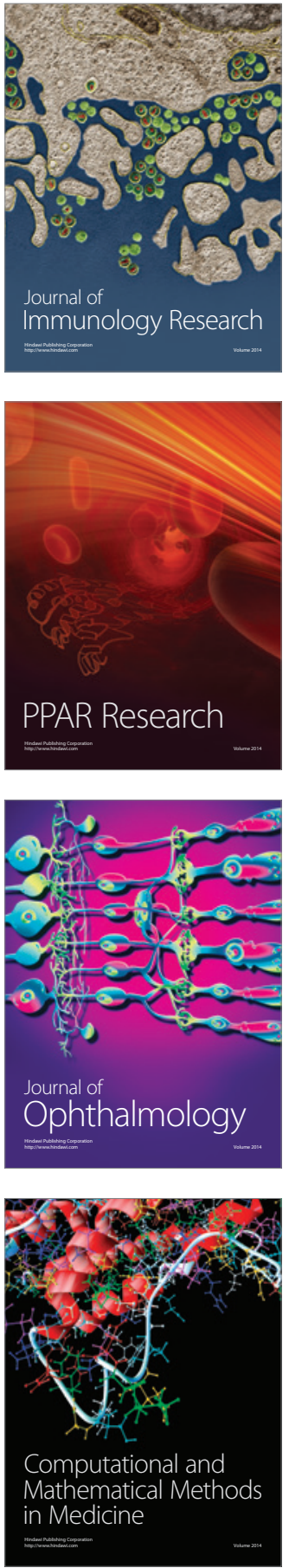

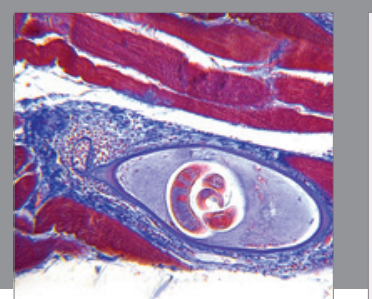

Gastroenterology Research and Practice

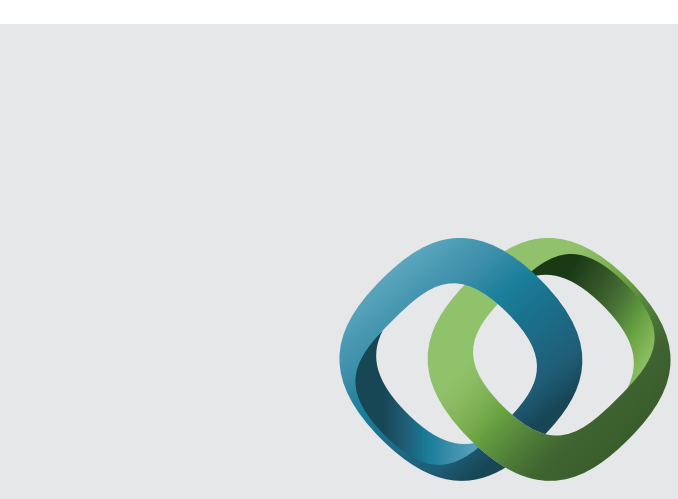

\section{Hindawi}

Submit your manuscripts at

http://www.hindawi.com
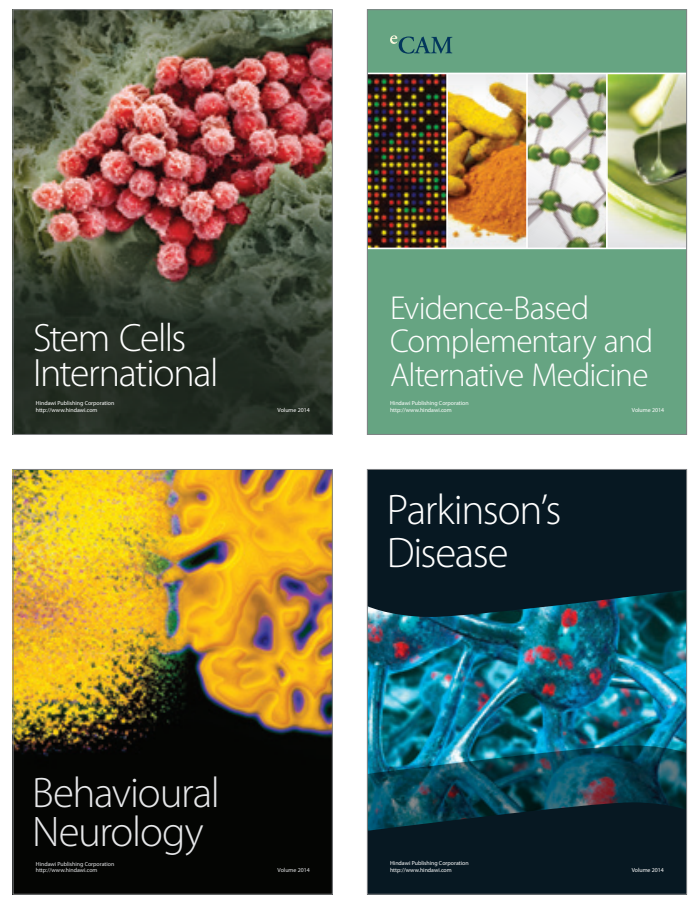
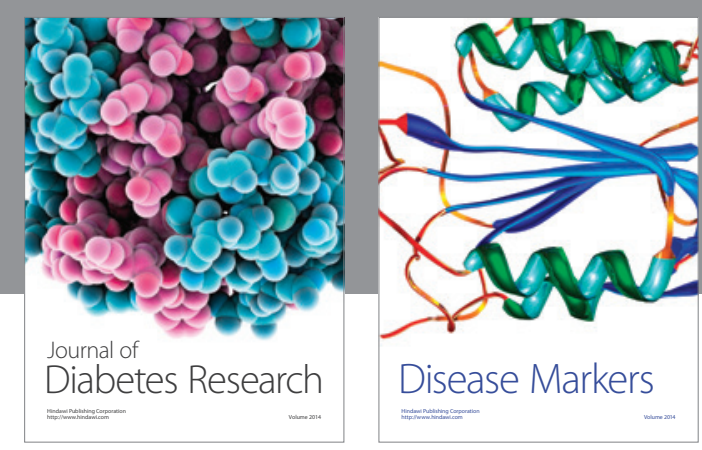

Disease Markers
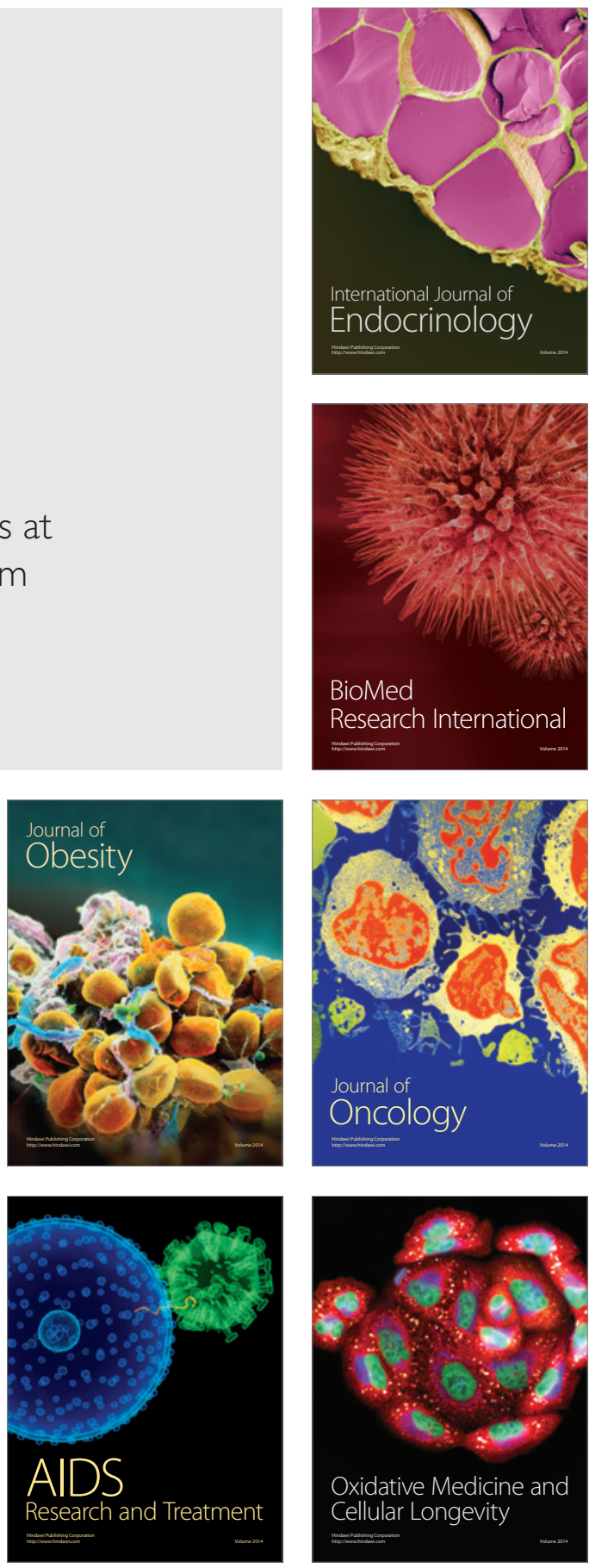